to oil. The Association's experimental slagging gasifier, built under contract with the Ministry of Power, at present consumes about a ton of fuel an hour and can take, in short tests, up to half of this in the form of pulverized coal. It has been operated successfully at various ash-levels and over a range of ash fluidities. Background studies have made possible the tentative correlation of slag viscosity-temperature curves with slag composition; and improved methods of analysis have enabled the important constituents of ash to be determined at the rate of four samples a day.

The automatically controlled small-pipe, forcedcirculation central heating system, developed by the Association, is being actively promoted by the Coal Utilization Council, and was displayed by them in the exhibition they had arranged on the site. Also on view in the Council's exhibition were some of the thirty or more designs of free-standing convector fire with restricted throat, a type of appliance that has been developed by the British Coal Utilization Research Association.

The Association's Calorimeter Room has taken its place as an absolute standard for testing domestic appliances. A method of automatic control for miniature chain-grate stokers, used to fire centralheating boilers ( $\frac{1}{2}-2$ million B.T.ण./hr.) in offices or blocks of flats, has been devised, and a unit burning $\frac{1}{2}$-in. small coal smokelessly and at high efficiency is now being tested.

An air-fuel ratio controller has been developed within the Association for fitting to stokers of Economic and Laneashire boilers in order to take much of the responsibility for maintaining the correct ratio of fuel to air out of the hands of the fireman, and one of these controllers was in use on the boiler used for site heating.

A first step towards finding means for reducing atmospheric pollution from coal-burning appliances has been made through the work on the measurement of dust and grit emission from boiler furnaces. The methods of sampling dust from stacks developed by the Association were on view and have aroused much interest in those concerned with enforcing or complying with the Clean Air Act. The automatic particle-sizing apparatus developed by the Association was displayed; with special care it can be employed down to 2 microns and can be used to carry out eight analyses a day.

The study of problems arising from the deposition of inorganic solids and corrosive liquids from flue gases in water-tube boilers forms an important part of the Association's work; these problems are investigated both in the laboratory and at power stations. Large- and small-scale equipment used in these investigations was on view. Special measuring apparatus devised for this work was also demonstrated.

It has not been possible in this short account to mention more than a selection of the exhibits. A fuller account of the current researches is contained in the annual report of the British Coal Utilization Research Association for 1958, and a bibliography of the Association's publications during 1938-59 is to be published in the near future.

\title{
THE EAR UNDER WATER
}

\begin{abstract}
A DISCUSSION meeting devoted to "The Ear A under Water" was held at the Royal Society on March 12. In his opening survey, Prof. O. Lowenstein pointed to the fact that even in its most highly evolved state the vertebrate ear is a dual-or evon triple-purpose sense organ. It incorporates receptors for angular acceleration (semicircular canals), for linear acceleration including gravitational stimuli (otolith organs) and for oscillatory changes in linear acceleration such as vibration in general and sound in particular (otolith organs, cochlea). The vertebrate ear appears to be a phylogenetic novelty derived by modification from the lateral-line organs of early fish-like vertebrates and not from the statocyst of the invertebrates. Thus, the ear is probably not the comparative-anatomical homologue of the invertebrate statocyst. There is no doubt, however, that the two organs are functionally analogous. It was therefore considered desirable to review recent work on the invertebrate statocyst in the context of the symposium.
\end{abstract}

Dr. Melvin Cohen (University of Oregon) described the anatomy of the statocyst of the lobster, Homarus americanus, and discussed the results of an electrophysiological analysis of its function. It contains two types of position receptors, one for the monitoring of absolute position and one which also indicates the direction from which a certain position is approached. A third receptor type functions as an acceleration receptor and is insensitive to position. There are receptors responding to vibration of the solid substrate, but no reactions to air-or water-borne sound could be registered. Dr. Cohen pointed to the striking similarities between the responses from the crustacean statocyst and those from the various end organs of the vertebrate labyrinth.

In a paper on the cephalopod statocyst, Prof. $J$. Z. Young gave a detailed description of the morphology of the statocyst of the octopus. This remarkable sense organ, too, shows a most interesting and functionally suggestive number of items of structural convergence with the vertebrate labyrinth. Apart from a vertically placed macula with otolith, there is a crista which has sections in three planes of space, each section being associated with a separate nerve. The sensory hairs are ensheathed in a matrix of unknown composition forming cupulæ reminiscent of those found in the labyrinth. Large neurons having dentritic endings as well as hair processes underlie the sensory cells of the crista and appear to make synaptic contact with them, although the hair cells themselves are primary sensory cells equipped with centripetal axons. A hand-shaped vane (the so-called anti-crista) protrudes into the endolymphatic space and seems to be so arranged as to protect the vertical section of the crista from overstimulation when the octopus suddenly accelerates forward, as it does on attacking prey.

Prof. Young stressed that there is no behavioural evidence of hearing in the cephalopods, but on anatomical grounds there is no reason why the cephalopod statocyst should not be potentially capable of vibration reception or even hearing, besides its manifestly obvious function as an organ of static and dynamic spatial orientation. 
The vertebrate ear evolved in aquatic animals, and it may well be that its function as a vibration receptor evolved simultaneously with that of an organ of orientation. As an introduction to the problems connected with hearing in aquatic vertebrates, Dr. P. Vigoureux (National Physical Laboratory, Teddington) gave a most useful survey of the physical aspects of sound propagation under water. So far as penetration of sound from air into water is concerned, there is a critical angle of $13^{\circ}$ of reflexion at the interface between air and water, and total reflexion occurs at all greater angles of incidence. Sound can therefore penetrate into water only if its incidence is almost vertical. Yet the human ear is sensitive enough to hear under-water sound from a powerful source in the air overhead. Dr. Vigoureux also discussed some effects of temperature gradients leading to conditions of exceptionally good sound propagation over long distances. Sound absorption is only 1/1000th part of what it is in air, and this is yet another reason for the considerably greater distance of sound propagation in water.

Prof. S. Dijkgraaf (Utrecht) introduced his account of hearing in bony fishes by a definition of sound and hearing. This has for a long time been a controversial matter and he advocated ascription of the ability of hearing to such animals as are sensitive to a suecession of pressure waves propagated with a characteristic velocity through the medium, be it air or water, and able to detect these stimuli by means of special receptors exclusively used for this purpose. If the latter condition is not fulfilled, one should speak of sound- or vibration-reception instead of hearing.

Prof. Dijkgraaf distinguished among the bony fishes between what he called 'specialists' and the normal run of fishes. The 'specialists', mostly freshwater fishes, have been shown to possess soundreinforcing structures like the Weberian ossicles or special gas chambers connected with the ear. Their frequency-range is considerable and they are more highly sensitive to tones than man up to a frequency of $1,000 \mathrm{c} / \mathrm{s}$. They are also capable of pitch discrimination over a limited range (up to $1,260 \mathrm{c.} / \mathrm{s}$.) and can discriminate frequency differences as low as 4 per cent. However, no evidence for directional hearing has so far been obtained. So-called normal fishes (almost all marine forms) have an upper limit of $400-1,000 \mathrm{c} . / \mathrm{s}$. and a much higher threshold.

In the second part of his paper, Prof. Dijkgraaf dealt with the problem of functional localization of hearing within the labyrinth of bony fishes and discussed the part played by the otolith organs in the sacculus and lagena in some, and the probable role of the utriculus in other forms, depending on differences in the nature and topographic deployment of the sound-reinforcing structures. Tactile skin receptors may be involved in the reception of lowfrequency sound, but there is no evidence for the collaboration of the lateral line.

In higher vertebrates the ear became adapted to the reception of airborne sound. The special matehing devices of the middle ear and the range-finding pinna of the mammals were evolved. Papers by Dr. Reysenbach de Haan (Eindhoven) on aspects of mammalian hearing under water and by Dr. F. C. Fraser and Mr. P. E. Purves of the British Museum on the osteology, acoustic matching, and evolution of air sinuses, and on muscular and vascular arrangements, acoustic isolation, and directionality of hearing, dealt with the way in which the Cetacea solved the problems of underwater hearing on their return to a fully aquatic existence.

Dr. Reysenbach de Haan pointed out that under water the external ear and the middle ear of the terrestrial mammal become useless. Man has no directional hearing under water and suffers a loss in hearing of $60 \mathrm{db}$. Whales and dolphins rely chiefly on sound for their orientation, and yet they have no outer ears and their auditory meatus has become highly modified. Dr. Reysenbach de Haan believes that the modified structures corresponding to the meatus are devoid of function, as the rate of transmission of sound in the tissues around the external auditory canal is practically equal to that in water. The bulla, however, is filled with air and kept hermetically sealed from the water outside. The striking feature of the middle ear or bulla is that it has parted company with the skull and, like the inner ear in the petromastoid, has come to hang loose under the skull. Foam-filled sinuses in the petromastoid are in communication with the air of the middle ear in the bulla and via the Eustachian tube with the air of the respiratory passages. The inner ear is thus completely air-insulated from the surrounding tissues, from the skull, and from the surrounding water. The two ears are also completely insulated from one another. This, Dr. Reysenbach de Haan held, was an indispensable condition for successful directional hearing under water.

Modifications of the middle ear and also of the cochlear structures were demonstrated to be associated with the sensitivity of the Cetacea to supersonic frequencies higher than 100,000 c./s. Cetaceans produce high-pitched sound and are known to echolocate like bats. In water, with the four times longer wave-length, much higher frequencies are necessary for the detection of objects of the same size.

Experiments on the directional hearing of dolphins and the methods used in the capture of these animals in Danish waters and their transport to the Netherlands were illustrated by a film made by $W$. $H$. Dudok Van Heel (Holland).

In their communication on the anatomy and function of the cetacean ear, Dr. F. C. Fraser and Mr. P. E. Purves, of the British Museum of Natural History, dealt with the morphology of the auditory meatus in toothed whales and whalebone whales. They have come to the conclusion, contrary to the opinion voiced by Dr. Reysenbach de Haan, that the meatus is not devoid of function. They believe that it plays an important part in sound conduction.

Experiments on a large portion of the squamomastoid region of a fin whale, preserved by deepfreezing and dissected after thawing to expose the middle ear, the wax plug and meatus, showed that the attenuation of high-frequency sound waves $(100,000 \mathrm{c} . / \mathrm{s}$.) was considerably lower when conduction followed the meatus with its lengthwise orientated fibre system, than in the surrounding tissues in which the fibrous structures are randomly orientated. The authors assumed that sound trans. mitted by the meatal path would be dominant at any level of intensity. The animal must be subjected to an intensity and/or phase difference at the cochlex of the two ears due to the screening effect of the head and the distance separating the two meatal openings. This may be of vital importance for directional hearing.

A detailed description of the air sinuses and peculiaritios of the vaseular system served to em- 
phasize the acoustic isolation of ear from skull and jaws and ear from ear. The part played by the albuminous foam formed by nitrogen in an oil-mucus emulsion was discussed, and it was shown how this foam can remain persistent even during a prolonged dive.

Finally the modifications of the middle ear ossicles were described with reference to the requirement for successful matching of the cetacean ear to water- borne sound. They were illustrated by a working model.

A series of anatomical exhibits was shown to illustrate the specialization in the topographic relationship between ear and skull, especially the arrangement of air sinuses in the various cetaceans.

The contributions to the symposium will be published in full in the Proceedings of the Royal Society.

O. LoWENSTEIN

\section{THE INDIAN ASSOCIATION FOR THE CULTIVATION OF SCIENCE}

\begin{abstract}
7 HE annual report for 1957-58 of the Indian Association for the Cultivation of Science*, which includes lists of papers published during the year under their departmental headings, records further work on the thermal diffusion and inter-diffusion of gases. An apparatus has been designed for measuring the thermal conductivity of diffusing gases and a new apparatus constructed for purifying high-pressure cornmercial hydrogen. The dimensions of the unit cell of naphthazarin have been re-determined by X-ray methods and further work on the molecular structure of this crystal is in progress. The work of the Department of Magnetism was reorganized and the study of paramagnetic anisotropy of dihalides of copper(II), the paramagnetic behaviour of fluosilicates and chlorostannates of copper(II) and meas. urement of the principal susceptibilities of paramagnetic crystals down to liquid-hydrogen temperatures has been undertaken, as well as the study of paramagnetic crystals both by the paramagnetic electron resonance and the proton resonance method. The anisotropy of many nickel(II) salts of similar constitution was studied to ascertain the effect of long-range crystalline fields in these salts, and work on paramagnetic alums of titanium(III), vanadium(III) and chromium(III) was completed.

In the Opties Department the Raman spectra of o-chlorophenol in different solvents, of $\alpha$ - and $\gamma$-picoline and their solutions in alcohol in liquid and solid state, and of ethylbenzene, chlorobenzene and bromobenzene in the frozen state at $-180^{\circ} \mathrm{C}$. have been determined and the ultra-violet absorption spectra of many aromatic compounds studied in the vapour, liquid and solid states, as well as those of

* Indian Association for the Cultivation of Science. Annual Report for 1957-59. Pp. 52. (Jadavpur, Calcutta : Indian Association for the Cultivation of Science, 1959.)
\end{abstract}

frozen 0.2 per cent and 25 per cent solutions of the dichlorobenzenes in iso-butyl alcohol at $-180^{\circ} \mathrm{C}$. and the Debye-Scherrer patterns due to frozen toluene, chlorobenzene and bromobenzene and to diphenyl at $32^{\circ} \mathrm{C}$. and at $-180^{\circ} \mathrm{C}$. The Department of Theoretical Physics was concerned mainly with the spin of an electron from five-dimensional wave equations, the influence of constant electric and magnetic fields on the spin of the particle, electronic energy bonds in lattices and some generalizations in relativistic cosmology.

In the Department of Physical Chemistry, investigations in high polymer chemistry related to the kinetics and chain transfer behaviour of methyl isopropenyl ketone, the aqueous polymerization of vinyl monomers in redox systems, the thermodynamic properties of binary mixtures, the determination of absolute values of the rate constants in polymerization and the preparation and properties of soil conditions of the krillium type. In general and analytical chemistry, work is being carried out on the mutual solubilization of oils and water, the decomposition of peroxides in different solvents and the velocity of ultrasonic waves in solutions and liquids. An apparatus has been assembled for determining the mutual solubilities of organic compounds in situ. The Department of Organic Chemistry continued its investigations on sesquiterpenoids, diterpenoids, triterpenoids and steroids, and in the Department of Inorganic Chemistry attention was concentrated on the study of co-ordination complexes and their applications in analytical ehemistry. It has been shown that 3- and 5-oximinomethylsalicylic acids and 3- and 5-aldehydosalicylic acids can be used for estimating thorium and its separation from the cerite earths.

\section{THE EAST AFRICAN INDUSTRIAL RESEARCH ORGANIZATION REPORT FOR 1957-58}

\begin{abstract}
THE annual report for 1957-58 of the East African Industrial Research Organization* records the official opening of the new headquarters of the Organization in Nairobi on February 14, 1958, and spectacular results from a close collaborative study by the Fuel Advisory Service with the Research and Economy Section of the Chief Mechanical Engineer's Department of the East African Railways and Harbours, notably in the design of a special burner for lighting up locornotive boilers and in increasing the power developed by locomotive engines

* East Africa High Commission. East African Industrial Research Organization Annual Report, 1957-1958. Pp. iit18. (Nairobi Government Printer, 1958.) Sh. 2.
\end{abstract}

in service, using a Giesil ejector. Advice was also given on the utilization of wood waste, and fuel economies of 5-20 per cent were demonstrated in some thirty factories. An oil-fired incinerator was designed for the new swine fever research centre at Mugaga and a similar but larger one for the new Welleome Foot-and-Mouth Disease Centre.

The Department of Fuel Technology and Chemical Engineering has also examined the use of solar driers and the dust-proofing of motor cars. Extensive work on the mechanical drying of Arabicz coffee has shown that damage is reduced by pre-drying and increased by increasing the final drying temperatures, and that, daylight has a marked effect on the liquoring quality 